\title{
The Relationship between Resistin Level and the Degree of Non-Alcoholic Fatty Liver Disease (NAFLD)
}

\section{Chairunnisa Fitri Marpaung ${ }^{1}$, Gontar Alamsyah Siregar ${ }^{2}$, Dharma Lindarto ${ }^{3}$, Ilhamd ${ }^{2}$}

\author{
${ }^{1}$ Department of Internal Medicine, Faculty of Medicine, Universitas Sumatera Utara, Medan \\ ${ }^{2}$ Division of Gastroentero-hepatology, Department of Internal Medicine, Faculty of Medicine, \\ Universitas Sumatera Utara, Medan \\ ${ }^{3}$ Division of Metabolic and Endocrinology, Department of Internal Medicine, Faculty of Medicine, Universitas \\ Sumatera Utara, Medan \\ Corresponding Author: Gontar Alamsyah Siregar
}

\begin{abstract}
Background: NAFLD is a metabolic syndrome that manifests in the liver and is associated with type 2 diabetes mellitus (type $2 \mathrm{DM}$ ), insulin resistance, obesity and hyperlipidemia. The number of sufferers continues to increase worldwide in line with the increasing prevalence of obesity and diabetes. Resistin is a potential marker for NAFLD, which also have an important relationship with obesity and insulin resistance.

Purpose: to analyze the relationship between resistin level and the degree of NAFLD.

Methods: This cross sectional study was conducted at the Gastroentero-hepatology Department of Haji Adam Malik General Hospital, Medan, from January to March 2020. Patients with NAFLD diagnosed with abdominal ultrasound underwent measurement of body mass index (BMI), examination of resistin levels, fasting blood glucose, platelet count, albumin, AST and ALT, and the degree of NAFLD Fibrosis Score (NFS) was determined.
\end{abstract}

Results: From 67 samples, based on abdominal ultrasound, the largest proportion was grade I NAFLD (40.4\%). There was a statistically significant relationship between resistin levels and the degree of NAFLD ( $\mathrm{p}$ value $<0.01$ ), NAFLD comorbid in both type $2 \mathrm{DM}$ and BMI $\geq 23 \mathrm{~kg} / \mathrm{m}^{2}$ ( $\mathrm{p}$ value $<0.001$ ), NFS with the degree of NAFLD ( $p$ value $<0.001$ ), and also resistin levels with the degree of NFS ( $p$ value $<0.001$ ).

Conclusion: Significant relationship was found between resistin level and the degree of NAFLD ( $p$ value $<0.001$ ) and also between resistin levels and the degree of NAFLD Fibrosis Score (NFS) (p value $<0.001$ )

Keywords: resistin, NAFLD, NFS, diabetes

\section{INTRODUCTION}

Non-alcoholic fatty liver disease (NAFLD) is a condition that covers the entire clinical spectrum from fatty liver/simple steatosis to steatohepatitis and cirrhosis without a history of significant alcohol consumption. ${ }^{[1]}$ NAFLD is found in $30 \%$ of the general population and $40-70 \%$ in obese patients. ${ }^{[2]}$ According to the European Association for the Study of the Liver (EASL, 2016) the prevalence in the general population is $17-46 \% .{ }^{[3]}$ NAFLD is a metabolic syndrome that manifests in the liver and is associated with type 2 DM, insulin resistance, obesity and hyperlipidemia. ${ }^{[4]}$ The number of sufferers continues to increase worldwide in line with the increasing prevalence of obesity and type $2 \mathrm{DM}$. The prevalence of NAFLD in people with diabetes is $59.67 \% .^{[5]}$ The more worrying clinical problem of the increasing prevalence of NAFLD is its progression 
which can progress to cirrhosis, liver failure, even hepatocellular carcinoma. ${ }^{[6]}$

Liver ultrasonography (USG) is a non-invasive diagnostic tool that is widely used in NAFLD. USG's sensitivity was $84.8 \%$ and its specificity was $93.6 \%$ in detecting steatosis. ${ }^{[7]}$ However, the results are operator dependent. Percutaneous liver biopsy remains the gold standard of NAFLD diagnostics, but it is an expensive, invasive, often misinterpreted procedure, and also complicated by pneumothorax, bleeding and puncturing of other visceral organ. ${ }^{[8]}$

Research on non-invasive diagnostic tools to identify potential biomarkers for NAFLD is also being developed. One marker that has the potential to be a marker for NAFLD is resistin, a cytokine released from adipose tissue called adipokines. Adipokine is believed to have an important relationship between obesity, insulin resistance, and NAFLD. ${ }^{[9]}$ Based on the literature search conducted by the author, there are still many differences in results obtained from the relationship between resistin levels and the degree of NAFLD. In Indonesia, no previous research has been published looking for a relationship between resistin levels and the degree of NAFLD, so we aimed to find the relationship between resistin levels and the degree of NAFLD.

\section{METHODS}

The study design was cross sectional, carried out in the Integrated Diagnostic Installation of Gastroenterohepatology Department in Haji Adam Malik Hospital Medan and the network hospital after obtaining the approval of the Health Research Ethics Commission. The research subjects were NAFLD patients who came to Haji Adam Malik Hospital and the Faculty of Medicine of Sumatera Utara University Hospital from January to March 2020, were taken by consecutive sampling. Inclusion criteria were age 18 years, diagnosed with NAFLD from anamnesis, laboratory examination and abdominal ultrasound, received information and consent to participate voluntarily to undergo physical examination, laboratory, and ultrasound. Exclusion criteria were suffering from hepatitis $\mathrm{B}$ or $\mathrm{C}$, malignancy or autoimmune disease, patients $<18$ years, pregnant women, alcohol consumption $>30 \mathrm{~g} /$ day in men and $>20 \mathrm{~g} /$ day in women, patients are not cooperative. With a confidence level of $95 \%$, a minimum sample size of 42 people is required.

Abdominal ultrasound examination is carried out by one operator who has the competence in ultrasound examination to confirm the image of NAFLD. If the results of the examination are inconclusive, then the diagnosis of NAFLD is carried out by 2 competent operators. The appearance of NAFLD on ultrasound is at least two of the following findings: increased hepato-renal contrast, bright liver texture, deep beam attenuation, vascular blurring and gall bladder wall definition. Then we determined the degree of NAFLD: (i) grade I: liver echogenicity diffusely increased but periportal and diaphragm is still quite good; (ii) grade II: diffuse increase in liver echogenicity which obscures peri-portal echogenicity but diaphragmatic echogenicity is still quite good; and (iii) grade III: increase in liver echogenicity diffuse blurs the peri-portal as well as the echogenicity of the diaphragm. Furthermore, measurement of height and weight to evaluate BMI, laboratory tests, include resistin, fasting blood glucose, platelet count, albumin, AST and ALT. The results of these tests were then entered into the NAFLD Fibrosis Score (NFS) formula to classify the predicted liver fibrosis.

Data analysis of the relationship between resistin levels and the degree of NAFLD, the relationship between NFS and the degree of NAFLD and the relationship between resistin levels and NFS used the Anova test if the data were normally distributed or Kruskal-Walis test if the data were not normally distributed. The relationship between comorbid and the degree of NAFLD used Chi-square test if the data were normally distributed or Fisher Exact test would be used for not normally 
distributed data. As for the comorbid relationship with resistin levels, the Independent T-test will be used if the data is normally distributed and will be replaced with the Mann-Whitney $U$ test if the data is not normally distributed. The analysis result is significant if the $\mathrm{p}$ value $<0.05$.

\section{RESULTS}

Sixty seven patients met the inclusion criteria included in this study, 41 patients $(61 \%)$ were male with a mean age of 42.08 years. The majority of respondents are Batak ethnic 37 (55\%), 30 employees (44\%), and the highest level of education is high school 31 (53.3\%). The most comorbid encountered were type 2 DM 33 (49.25\% of the total sample), BMI $\geq 23 \mathrm{~kg} / \mathrm{m}^{2}$ (overweight) 34 (50.74\%) and hypertension $15(22.3 \%)$.

Table 1. Demographic and clinical characteristics of research subjects

\begin{tabular}{|l|l|}
\hline Characteristics & $\mathbf{n}=\mathbf{6 7}$ \\
\hline Gender & \\
- Male & $41(61,1)$ \\
- Female & $26(38,8)$ \\
\hline Age, mean (SD), years & $42,08(11,8)$ \\
\hline Ethnic & \\
- Batak & $37(55)$ \\
- Javanese & $24(35)$ \\
- Aceh & $6(8)$ \\
\hline Occupation & \\
- Employees & $30(44)$ \\
- Housewife & $15(22)$ \\
- Entrepreneur & $17(25)$ \\
- Civil servants & $5(7)$ \\
\hline Education & \\
- Elementary school & $3(4)$ \\
- Middle school & $15(22)$ \\
- High school & $31(46)$ \\
- University & $18(26)$ \\
\hline Comorbid & \\
\hline - Type 2 DM & $33(49,25)$ \\
- IMT $\geq 23 \mathrm{~kg} / \mathrm{m}^{2}$ & $34(50,74)$ \\
- Hypertension & $15(22,30)$ \\
\hline
\end{tabular}

From the results of abdominal ultrasound, it was found that the highest number was grade I NAFLD (40.4\%), followed by NAFLD grade II and III, $29.8 \%$ respectively.

Table 2. Degrees of NAFLD

\begin{tabular}{|l|l|l|l|l|}
\hline Variable & \multicolumn{3}{|l|}{ Degree of Severity } & Total \\
\hline & Grade I & Grade II & Grade III & \\
\hline NAFLD & $27(40,4 \%)$ & $20(29,8 \%)$ & $20(29,8 \%)$ & $67(100 \%)$ \\
\hline
\end{tabular}

By using the Kruskal Wallis test, it was found that there was a relationship between resistin levels and the degree of NAFLD, with a statistically significant result ( $\mathrm{p}$ value $<0.01$ ).

Table 3. Relationship between resistin levels and NAFLD degrees

\begin{tabular}{|l|l|l|}
\hline & $\begin{array}{l}\text { Resistin (ng/ml), median (min- } \\
\text { max) }\end{array}$ & p value \\
\hline NAFLD grade I & $2,60(2,02-3,81)$ & \multirow{2}{*}{$<0,001 *$} \\
\cline { 1 - 2 } NAFLD grade II & $2,51(2,14-2,92)$ & \\
\hline NAFLD grade III & $3,81(2,92-4.98)$ \\
\hline \multicolumn{2}{|c|}{$*$ Kruskal walis } \\
\hline
\end{tabular}

The resistin levels between degrees of NAFLD can be seen more clearly in the diagram below.

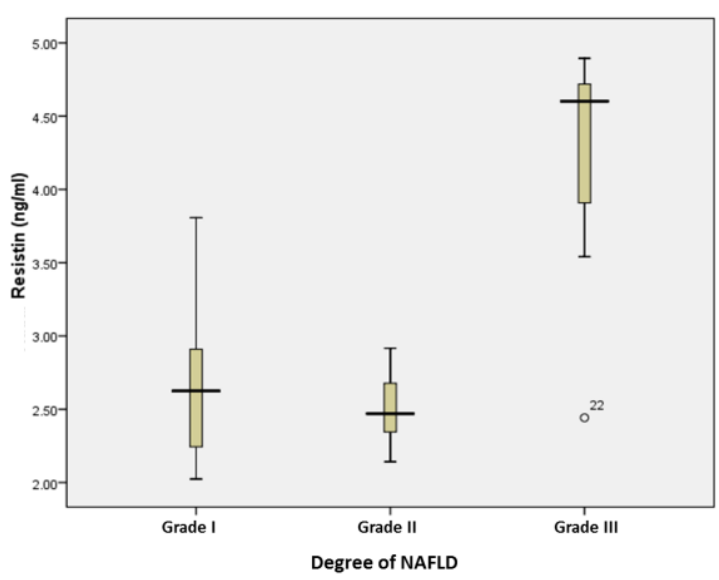

Figure 1. Differences in resistin levels between NAFLD degrees

In this study, the comorbid encountered were type $2 \mathrm{DM}, \mathrm{BMI} \geq 23$ $\mathrm{kg} / \mathrm{m}^{2}$, and hypertension. Both type $2 \mathrm{DM}$ and $\mathrm{BMI} \geq 23 \mathrm{~kg} / \mathrm{m}^{2}$, by Fisher exact test had a significant relationship with $\mathrm{p}$ value < 0.001 .

Table 4. Relationship of comorbid with NAFLD

\begin{tabular}{|c|c|c|c|c|c|}
\hline Comorbid & NAFLD Grade I (\%) & NAFLD Grade II (\%) & NAFLD Grade III (\%) & Total & p value \\
\hline \multicolumn{6}{|l|}{ Type 2 DM } \\
\hline Yes & $6(8.9)$ & $14(20.8)$ & $17(25)$ & $37(55.2)$ & \multirow[t]{2}{*}{$<0.001^{*}$} \\
\hline No & $21(31.3)$ & $6(8.9)$ & $3(4.4)$ & $30(44.8)$ & \\
\hline \multicolumn{6}{|c|}{$\mathrm{BMI} \geq 23 \mathrm{~kg} / \mathrm{m}^{2}$} \\
\hline Yes & $5(7.4)$ & $13(19.4)$ & $16(23.8)$ & $34(50.8)$ & \multirow[t]{2}{*}{$<0.001^{*}$} \\
\hline No & $22(32.8)$ & $7(10.4)$ & $4(5.9)$ & $33(49.2)$ & \\
\hline \multicolumn{6}{|c|}{ Hypertension } \\
\hline Yes & $5(7.4)$ & $4(5.9)$ & $6(8.9)$ & $15(22.3)$ & \multirow[t]{2}{*}{$0.93^{*}$} \\
\hline No & $22(32.8)$ & $16(23.8)$ & $14(20.8)$ & $52(77.7)$ & \\
\hline
\end{tabular}


In samples with comorbid type 2 DM, resistin level median was higher than those without comorbid type $2 \mathrm{DM}[3.43$ (2.14-4.89) and 2.64 (2.02-4.68) $\mathrm{ng} / \mathrm{ml}$, respectively]. In the group with $\mathrm{BMI} \geq 23$ $\mathrm{kg} / \mathrm{m}^{2}$ (overweight), resistin level median was also found to be higher [3.42 (2.144.89) $\mathrm{ng} / \mathrm{ml}$. In type $2 \mathrm{DM}$ and BMI $\geq 23$ $\mathrm{kg} / \mathrm{m}^{2}$, by Mann Whitney test, both had a significant relationship with $\mathrm{p}$ value $<0.001$.

Table 4.5 Correlation between comorbid and resistin Levels \begin{tabular}{|l|l|l|}
\hline Comorbid & Resistin (ng/ml), median (min-max) & $p$ value \\
\hline
\end{tabular} Type 2 DM

\begin{tabular}{|l|l|l|}
\hline Yes & $3,43(2,14-4,89)$ & $<0,001^{*}$ \\
\hline No & $2,64(2,02-4,68)$ & \\
\hline BMI & $<0,001^{*}$ \\
\hline$\geq 23 \mathrm{~kg} / \mathrm{m}^{2}$ & $3,42(2,14-4,89)$ & \\
\hline$<23 \mathrm{~kg} / \mathrm{m}^{2}$ & $2,73(2,02-4,77)$ & $<$ \\
\hline
\end{tabular}

* Mann Whitney U-test

We also assessed the mean of the NFS parameters.

Table 6. NFS assessment parameters

Table 6. NFS assessment parameters
\begin{tabular}{|l|l|}
\hline Parameters & $24.02(19.32-33.59)$ \\
\hline BMI, median (min-max), $\mathrm{kg} / \mathrm{m}^{2}$ & $210,(98-310)$ \\
\hline $\begin{array}{l}\text { Random blood glucose level, median } \\
\text { (min-max), mg/dl }\end{array}$ & $1,4(0.87-2.20)$ \\
\hline AST/ALT ratio, median (min-max) & $220(89-398)$ \\
\hline Platelet, median (min-max), $\mathrm{x} 10^{3} / \mathrm{mm}^{3}$ & $3,3(2.5-4.6)$ \\
\hline Albumin, (min-max), mg/dl & $3,08(2,02-4,89)$ \\
\hline Resistin, median (min-max), $\mathrm{ng} / \mathrm{ml}$ & \\
\hline
\end{tabular}

Cross tabulation was carried out between NFS and the degree of NAFLD and tested with Kruskal Wallis, both had a significant relationship with $\mathrm{p}$ value $<0.001$.

Table 7. Relationship between NFS and NAFLD Degrees

\begin{tabular}{|l|l|l|}
\hline NAFLD & NFS median (min-max) & p value \\
\hline Grade I & $-1.966(-4.293-3.190)$ & $<0,001^{*}$ \\
Grade II & $-0.422(-4.326-1.189)$ & \\
Grade III & $1.323(-1.926-3.524)$ & \\
\hline
\end{tabular}

* Kruskal Wallis

By using the Kruskal Wallis test, it was found that there was a relationship between resistin levels and the degree of NFS with a statistically significant result ( $p$ value $<0.001)$. The mean resistin level in the Low group $(<-1,445)$ was $2.68(2.02-4.68)$ $\mathrm{ng} / \mathrm{ml}$, in Intermediate group (1.4465-0.676) was $2.84(2.14$ - 4.77) $\mathrm{ng} / \mathrm{ml}$ and in Advanced group (> 0.676) was 4.03 (2.24 4.89) $\mathrm{ng} / \mathrm{ml}$.
Table 8. Relationship between resistin levels and NFS

\begin{tabular}{|l|l|l|}
\hline & $\begin{array}{l}\text { Resistin, median, } \\
\text { ng/ml value }\end{array}$ & p \\
\hline Low $(<-1,445)$ & $2,68(2,02-4,68)$ & $<0,001 *$ \\
Intermediate $(-1,445-0,676)$ & $2,84(2,14-4,77)$ & \\
Advanced $(>0,676)$ & $4,03(2.25-4,89)$ & \\
\hline \multicolumn{2}{|c}{$*$ Kruskal Wallis }
\end{tabular}

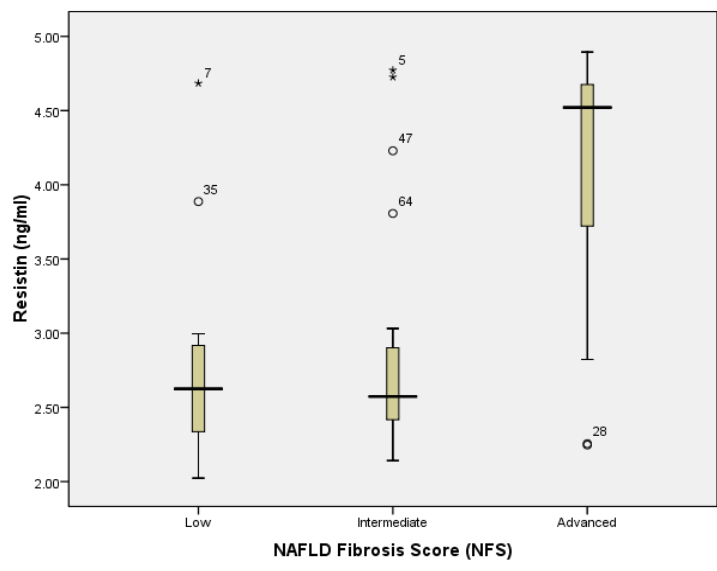

Figure 2. Difference in resistin Levels between NAFLD Fibrosis Score (NFS) categories

\section{DISCUSSION}

Number of men who suffered from NAFLD was more than women from this study were 41 patients (61\%), with mean age 42.08 years old, which is classified as productive age. These results are consistent with previous studies. Monem et al found that men suffered more from NAFLD for $68 \%,{ }^{[10]}$ while study by Siregar G.A. in Medan reported that $55 \%$ of subjects with NAFLD were women, but these results were not significant, with $\mathrm{p}$ value $=0.232 .^{[11]} \mathrm{In}$ this study, the highest number of patients with grade I NAFLD was 27 patients (40.4\%), followed by NAFLD degrees II and III, respectively $29.8 \%$. Not many NAFLD studies have used abdominal ultrasound, most confirmed by biopsy. However, in this study, the degree of NAFLD was determined based on the results of ultrasound conducted by experienced experts.

The degree of NAFLD in this study has a relationship with resistin levels with a statistically significant result ( $\mathrm{p}$ value $<0.001)$. The median serum resistin level in the grade I, II, and III NAFLD group was $2.60 \mathrm{ng} / \mathrm{ml}, 2.51 \mathrm{ng} / \mathrm{ml}$, and $4.29 \mathrm{ng} / \mathrm{ml}$, respectively. Many studies have previously been conducted to assess the relationship 
between resistin and NAFLD. These studies have generally compared the NAFLD group to the control. Most use biopsy modality to confirm the diagnosis of NAFLD. Meanwhile, the relationship with the degree of NAFLD based on abdominal ultrasound research is still quite limited.

Study by Mohamed et al. also found a significant difference between NAFLD group $(16.2 \pm 4)$ and the control group (3.4 $\pm 1.1) .{ }^{[12]}$ In that study, the cut point of resistin levels for NAFLD was > 3.7 $\mathrm{ng} / \mathrm{ml},{ }^{[10]}$ while in this study, the average resistin level was lower than the cut point, starting from 2.60 in grade I NAFLD, while in grade III NAFLD the average resistin level was found to be higher $(4.29 \mathrm{ng} / \mathrm{ml})$.

Pagano et al. obtained a comparison between NAFLD group $(5.87 \pm 0.49 \mathrm{ng} /$ $\mathrm{ml})$ and the control group (4.30 $\pm 0.20 \mathrm{ng} /$ $\mathrm{ml}$ ) showed a significant difference, and they also said that at the steatohepatitis stage, higher resistin levels were found compared to those with pure fatty liver. ${ }^{[13]}$ This suggests that the higher the progression of the NAFLD degree, the higher the resistin level. In line with Pagano et al., Mohamed et al. reported differences in levels of resistin in patients with NAFLD subtype in which NASH patients (mean \pm $\mathrm{SD}=19.2 \pm 3.6 \mathrm{ng} / \mathrm{ml}$ ) had higher resistin than non-NASH patients (mean $\pm \mathrm{SD}=13.5$ $\pm 2.7 \mathrm{ng} / \mathrm{ml}$ ) with a significant difference among them. ${ }^{[12]}$ In contrast to Pagano et al. and Mohamed et al, Shen et al, obtained resistin levels in the NASH group were higher than in the NAFLD group but there were no significant differences in the NAFLD subtype. ${ }^{[14]}$

In addition, a seven-year prospective study by Musso et al. demonstrated that resistin levels were not associated with progression and grade of NAFLD. ${ }^{[15]}$ A systematic review by Bekaert $\mathrm{M}$, et al, suggested that from 12 studies investigating the association between resistin and liver histological parameters in NAFLD, only 6 reported significant differences. Among these, the strongest association was with the degree of steatosis and then with portal abnormalities. $^{[16]}$ Finally, in a recent evaluation of plasma biomarkers in a large, well-characterized biopsy evidenced by a large population of NAFLD $(n=648)$ by the NASH Clinical Research Network, resistin level was similar in patients with a definite diagnosis of NASH than in healthy subjects, but higher in patients with stage 2 to 4 fibrosis versus 0 to 1 (odds ratio, 1.12). ${ }^{[17]}$ These findings confirm previous results from observations with smaller sample sizes, who reported higher resistin levels in patients with histologically proven NAFLD and advanced fibrosis. ${ }^{[18]}$ These results suggest that resistin cannot be used to differentiate between $\mathrm{SS}$ and NASH, but resistin may have a diagnostic value for differentiating between the different stages of NAFLD.

In this study, the comorbid encountered were type $2 \mathrm{DM}, \mathrm{BMI} \geq 23$ $\mathrm{kg} / \mathrm{m}^{2}$, and hypertension, as many as 37 people (55\%) with type 2 DM. In this study, there was a significant relationship ( $\mathrm{p}$ value $<0.001$ ) between comorbid type $2 \mathrm{DM}$ with degrees of NAFLD. Research by Monem et al. also found the same results, there was a relationship between type $2 \mathrm{DM}$ and NAFLD. ${ }^{[19]}$ Senates et al. also found that there was a relationship between type $2 \mathrm{DM}$ and NAFLD $(\mathrm{p}$ value $=0.03$ ) where type 2 DM was found in $32.8 \%$ of the samples.

BMI $\geq 23 \mathrm{~kg} / \mathrm{m}^{2}$ was found in 33 samples, and there was a relationship between BMI and the degree of NAFLD where the results of Mann Whitney test obtained $p$ value $<0.01$. This is in line with the study by Monem et al, who found the same results that there was a relationship between overweight and NAFLD ( $p$ value $<0.001)$. Murad et al. also found that NAFLD patients tended to be fatter (BMI $26.48 \pm 3.11 \mathrm{~kg} / \mathrm{m}^{2}$ ) with $\mathrm{p}$ value $<0.001$. $^{[20]}$ AST/ALT ratio in this study was higher than the results found in the study by Rufillo $\mathrm{G}$, et al, where the mean AST/ALT ratio was $0.67 \pm 0.23$. Mean albumin was 4.0 $4.54 \mathrm{mg} / \mathrm{dl}$, meanwhile for the platelet count was $202-291\left(\times 10^{3}\right) / \mathrm{mm}^{3}{ }^{[21]}$ From all these parameters, the calculation of the NAFLD 
Fibrosis Score (NFS) with the formula $1.657+0.037 \mathrm{x}$ age (years) $+0.094 \mathrm{x}$ BMI $\left(\mathrm{kg} / \mathrm{m}^{2}\right)+1.13 \times$ fasting blood glucose/DM $($ available $=1$, none $=0)+0.99 \times$ AST/ALT ratio $-0.013 \times$ platelet $(\mathrm{x} 109 / \mathrm{L})-0.66 \mathrm{x}$ albumin $(\mathrm{g} / \mathrm{dl})$, then the score was calculated and classified into low $(<-1.445)$, intermediate $(-1.4465-0.676)$, and advanced $(>0.676)$.

From the results of the Fisher exact test, it was found that there was a relationship between NFS and the degree of NAFLD ( $p$ value $<0.001$ ). Study by Angulo et al. showed that NFS is a fairly good scoring system with sensitivity of $77 \%$ and specificity of $77 \%$ in 32 patients $(47.7 \%)$. In this study, by Kruskal Wallis test, it was found that there was a relationship between resistin levels and the degree of NFS with a statistically significant result ( $p$ value $<0.01)$. The median serum resistin level in the low group $(<-1,445)$ was $2.68(2.02$ $4.68) \mathrm{ng} / \mathrm{ml}$, in the indeterminate group (1.4465 - 0.676) was 2.84 (2.14 - 4.77) $\mathrm{ng} / \mathrm{ml}$, and in the advanced group $(>0.676)$ was $4.03(2.24-4.89) \mathrm{ng} / \mathrm{ml}$. There have been no previous supporting research linking resistin levels with this NFS so that the results of this study cannot be compared with previous studies. It is necessary to carry out further studies with better study designs such as a prospective cohort to assess the relationship of resistin levels with NAFLD grade and NFS, so that the relationship can be known more definitely.

\section{CONCLUSIONS}

There was a significant relationship between resistin levels and the degree of NAFLD ( $p$ value $<0.001$ ). The results also showed a significant relationship between resistin levels and the degree of NAFLD Fibrosis Score (NFS) ( $p$ value $<0.001$ ).

\section{ACKNOWLEDGEMENTS}

The authors gratefully acknowledge that the present research is supported by the Ministry of Research and Technology and Higher Education Republic of Indonesia. The support is under the research grant
DRPM (Direktorat Riset dan Pengabdian Masyarakat).

Conflict of Interest: None

\section{Source of Funding: None}

\section{Ethical Approval: Approved}

\section{REFERENCES}

1. Chalasani N, Younossi Z, Lavine JE. The diagnosis and management of non-alcoholic fatty liver disease: practice guideline by the American Association for the Study of Liver Diseases, American College of Gastroenterology, and the American Gastroenterological Association. Hepatology. 2012; 55 (6): 2005-2012..

2. Boutari C, Perakakis N, Mantzoros CS. Association of Adipokines with Development and Progression of Nonalcoholic Fatty Liver Disease. Endocrinol Metab.2018; 33: 33-43.

3. EASL - EASD - EASO. Clinical Practice Guidelines for the management of non alcoholic fatty liver disease. J Hepatol. 2016. Available from: http://dx.doi.org/10.1016/j.jhep.2015.11.004

4. Yki JH. Non-alcoholic fatty liver disease as a cause and a consequence of metabolic syndrome. Lancet Diabetes Endocrinol. 2014; 2: 901-10. Available from: http://dx.doi.org/10.1016/S22138587(14)70032-4.

5. Dai W, Ye L, Liu A. Prevalence of nonalcoholic fatty liver disease in patients with type 2 diabetes mellitus a metaanalysis. Medicine. $2017 ; 96: 39$

6. Angulo P, Hui J M, Marchesini, G, et al. The NAFLD Fibrosis Score: A Non Invasive System That identifies Liver Fibrosis in patients with NAFLD. Hepatology. 2007; 45(47): 846-856.

7. Hernaez, R. Genetic factors associated with the presence and progression of nonalcoholic fatty liver disease: A narrative review. Gastroenterolhepatol.2012; 35 (1). 32-41.

8. Koutsogiannis D, Summers K, George B, Adams P, Marotta P, Chakrabarti S. Identification of serum biomarkers in end stage liver disease. The Open Biomarkers Journal. 2010; 3: 1-6. 
9. Polyzos, S.A. Kontouras, J., Mantzoros, C.S. Adipokines in nonalcoholic fatty liver disease. Clinical and Experimental Metabolism. 2016;1062-1079.

10. Monem, SMA, Fathy T, Shalaby, SM, et al. Serum Resistin Level as a Diagnostic Marker in Non-Alcoholic Steatohepatitis. Afro-Egypt J Infeed Endem Dis. 2018;8 (3). 140-148.

11. Siregar et al, $\mathrm{Br}$ Gurning Mariati. Relationship between Serum Vascular Endothelial Ghrowth Factor (VEGF) and Nonalcoholic Fatty Liver Disease. USU Institutional Repositoy.2018. Available from

http://repository.usu.ac.id/handle/12345678 9/12385

12. Mohamed, AA.,et al. Is there a role for resistin in the pathogenesis of polycystic ovary syndrome in Sudanese women? Bioscience Research. 2019; 16(2): 13631368

13. Pagano, C., Soardo, G., Pilon, C. et al. Increased Serum Resistin in Nonalcoholic Fatty Liver Disease is related to liver disease severity and not to insulin resistance. The Journal of Clinical Endocrinology and Metabolism. 2006;91 (3): 1081-1086.

14. Shen, C., Zhao, CY., Wang W, et al. The relationship between hepatic resistin overexpression and inflammation in patients with nonalcoholic steatohepatitis. MC GastroenterologyI. 2014; 1-8.

15. Musso, G., Cassader, M., Michieli,FD., et al. Nonalcoholic steatohepatitis versus steatosis: adipose tissue insulin resistance and dysfunctional response to fat ingestion predict liver injury and altered glucose and lipoprotein metabolism. Hepatology. 2012; 56(3):933-42

16. Bekaert M, Verhelst X, Geerts A, Lapauw B, Calders P. Association of recently described adipokines with liver histology in biopsy-proven non-alcoholic fatty liver disease: a systematic review. Obes Rev.2016; 17: 68-80.

17. Ajmera V, Perito ER, Bass NM, Terrault NA, Yates KP, Gill R, et al. Novel plasma biomarkers associated with liver disease severity in adults with nonalcoholic fatty liver disease. Hepatology. 2017; 65:65-77.

18. Jamali R, Razavizade M, Arj A, Aarabi MH. Serum adipokines might predict liver histology findings in non-alcoholic fatty liver disease. World J Gastroenterol.2016; 22: 5096-103.

19. Senates E, Colak Y, Yesil A, Coskunpinar O, Kahraman T, Erkalma B, et al. Circulating resistin is elevated in patients with non-alcoholic fatty liver disease and is associated with steatosis, portal in Ammation, insulin resistance and nonalcoholic steatohepatitis scores. Minerva Med. 2012: 103; 1.

20. Murrad A., Hasan H., Husein H., Serum resistin levels in nonalcoholic fatty liver disease and their relationship to severity of liver disease. Journal of Endocrinology, Metabolism and Diabetes of South Africa.2014; 15(1):53-56.

21. Rufillo G, Fassio E, Alvarez E, et al. Comparison of NAFLD fibrosis score and BARD score in predicting fibrosis in nonalcoholic fatty liver disease. Journal of Hepatology 2011;54: 160-163.

How to cite this article: Marpaung CF, Siregar GA, Lindarto $D$ et al. The relationship between resistin level and the degree of non-alcoholic fatty liver disease (NAFLD). International Journal of Research and Review. 2021; 8(7): 192-198. DOI: https://doi.org/10.52403/ijrr. 20210726 